\title{
SARS-CoV-2 Seroprevalence in People Referred to Private Medical Laboratories in Different Districts of Tehran, Iran from May 2020 to April 2021
}

\author{
Zahra Heydarifard $^{1} \cdot$ Sevrin Zadheidar ${ }^{1} \cdot$ Jila Yavarian $^{1} \cdot$ Shirin Kalantari $^{1} \cdot$ Ahmad Nejati $^{1} \cdot$ Talat Mokhtari-Azad $^{1} \cdot$ \\ Nazanin Zahra Shafiei-Jandaghi ${ }^{1}$
}

Received: 23 December 2020 / Accepted: 28 June 2021 / Published online: 30 September 2021

(c) Wuhan Institute of Virology, CAS 2021

\section{Dear Editor,}

The first cases of severe acute respiratory syndrome coronavirus 2 (SARS-CoV-2) in Iran were identified in Qom on February 19, 2020, which soon spread throughout the country (Yavarian et al. 2020). As of May 12, 2021, 2,691,352 confirmed cases of COVID-19 (the disease caused by SARS-CoV-2) and 75,568 associated deaths have been reported in the country by Iran Ministry of Health.

COVID-19 screening has been achieved by identifying the virus using real time PCR (RT-PCR) and detecting specific antibodies by serological methods (Patel et al. 2020). Although RT-PCR is perceived to be the gold standard assay for diagnosing SARS-CoV-2 infection, seroprevalence study is more likely to show the true number of SARS-CoV-2 infections since the beginning of the pandemic (Rostami et al. 2020). Moreover, it enables health authorities to surveil the seroconversion and implement more appropriate public health strategies (Rostami et al. 2020).

For SARS-CoV-2 antibody detection, a limited number of kits with acceptable sensitivity and specificity are available. These kits, may have both false positive and negative results (Watson et al. 2020). The cross-reactivity with other antibodies were shown (Abduljalil 2020). Moreover, a rapid reduction in IgG titers against SARS$\mathrm{CoV}-2$ among infected individuals has been reported. In fact, $12.9 \%$ of symptomatic and $40.0 \%$ of asymptomatic cases, became seronegative for IgG after 8 weeks from the initiation of the infection, which could lead to underestimating the seroprevalence of SARS-CoV-2 (Long et al.

Nazanin Zahra Shafiei-Jandaghi

nz-shafiei@tums.ac.ir

1 Virology Department, School of Public Health, Tehran University of Medical Sciences, Tehran 1417613151, Iran
2020). Nevertheless, in facing with pandemics, antibody detection is crucial to monitor virus circulation in populations. In Iran, serological tests of SARS-CoV-2 are available but data on seroprevalence of SARS-CoV-2 infection in Iran is limited.

This study are conducted to evaluate the prevalence of SARS-CoV-2 specific IgM and IgG in individuals referred to private laboratories in north, south, east, and west parts of Tehran (the capital of Iran), based on the sex, age groups, and regional districts of residence during 12 months.

To reach the goal, a cross-sectional study was conducted from May 1, 2020 to April 30, 2021 in Tehran. A total of 4786 samples were obtained from individuals who referred to four laboratories from the north, south, east, and west parts of the city for SARS-CoV-2 serological testing. All samples were tested in the local private laboratories with SARS-CoV-2 IgG and IgM ELISA Kits (Pishtaz Teb, Iran). These commercial kits had a sensitivity and specificity of $79.4 \%$ and $97.3 \%$ for IgM detection and $94.1 \%$ and $98.3 \%$ for IgG identification, respectively. The statistical analysis was performed using Statistical Package for Social Sciences (SPSS Inc., Chicago, Illinois, USA) version 26.0.

A total of 4786 individuals were participated in this study from 4 districts of Tehran, including 883 (18.4\%) from the east, 1763 (36.8\%) from the west, 1441 (30.2\%) from the north and $699(14.6 \%)$ from the south. Cases were divided into 5 age groups including 0 to $\leq 18$ years, 19 to $\leq 34$ years, 35 to $\leq 49$ years, 50 to $\leq 64$ years, and $\geq 65$ years. Of all cases, $2376(49.6 \%)$ were male and 2411 (50.4\%) were female. Among all participants, age group of 18 years and younger comprised the smallest fraction $(\mathrm{n}=435,9.1 \%)$, while the age group of $35-49$ years represented the largest proportion $(n=1627$, $34 \%)$. 
The results showed that, during May 1, 2020 to April 30, 2021, total prevalence of SARS-CoV-2 IgG was 1409/4786 (29.4\%), while IgM was detected in $786 / 4786$ (16.4\%) samples. It should be noted that 669/4786 (14\%) cases were positive for both $\operatorname{IgG}$ and $\operatorname{IgM}$. IgG seroprevalence among individuals in four different districts of the city was slightly different as follows: $23.5 \%$ in north, $29.8 \%$ in south, $32.4 \%$ in west and $33 \%$ in east $(P>0.05)$. During the period of 12 months, as time passed the rate of seroprevalence raised. This increase, from May 1 to October 31, 2020, compared to November 1, 2020 to April 30, 2021, was shown in Fig. 1A and 1B.

Assuming that the presence of $\operatorname{IgG}$ and IgM antibodies indicates the exposure to SARS-CoV-2, the results showed that by the end of April 2021 more than half of people in Tehran were still immunologically naive to SARS-CoV-2. Evaluation of age and gender in seropositive individuals showed older people ( $\geq 65$ years) had higher seropositivity than the other age groups, which was consistent with the findings in Italy and the USA that reported a high seroprevalence in the same age group (Havers et al. 2020; Vena et al. 2020). Similar to a previous research (Pollán et al. 2020), in this study, no difference in seroprevalence between females and males was detected (Table 1).

As the data on COVID-19 incidence and death rate in Tehran were not available, variation of SARS-CoV-2 seroprevalence using IgG and/or IgM positivity in this study was compared to the incidence and death rate of COVID-19 based on the reports by the Ministry of Health from all over the country during mentioned 12 months (https://irangov.ir/ministry-of-health-and-medical-educa tion) (Fig. 1C). This figure showed, during summer and autumn 2020, Iran faced the second and third peaks of disease incidence and associated death. While, the third peak was remarkably sharper than the second one, these two peaks were in concordance with the rise of seroprevalence identified in this study. Besides, the fourth peak of COVID-19 incidence, which was started in March 2021, was accompanied by the seroprevalence elevation found in the last month of the study performance.

Up to April 30, 2021, there was limited number of published studies on SARS-CoV-2 seroprevalence in Iran. One study was performed including 551 cases in Guilan in April, 2020, in which seroprevalence of SARS-CoV-2 was $22 \%$ in the region (Shakiba et al. 2020). Another study was performed on 8902 specimens which were collected from 18 cities in Iran including Tehran during April 17 to June 2, 2020. They showed the overall seroprevalence was $17.1 \%$, while it was $16.3 \%$ in Tehran (Poustchi et al. 2020). Herein, compared to other studies a higher rate of seroprevalence was reported in this city. Besides, the time duration of the study (the last 12 months before the start of
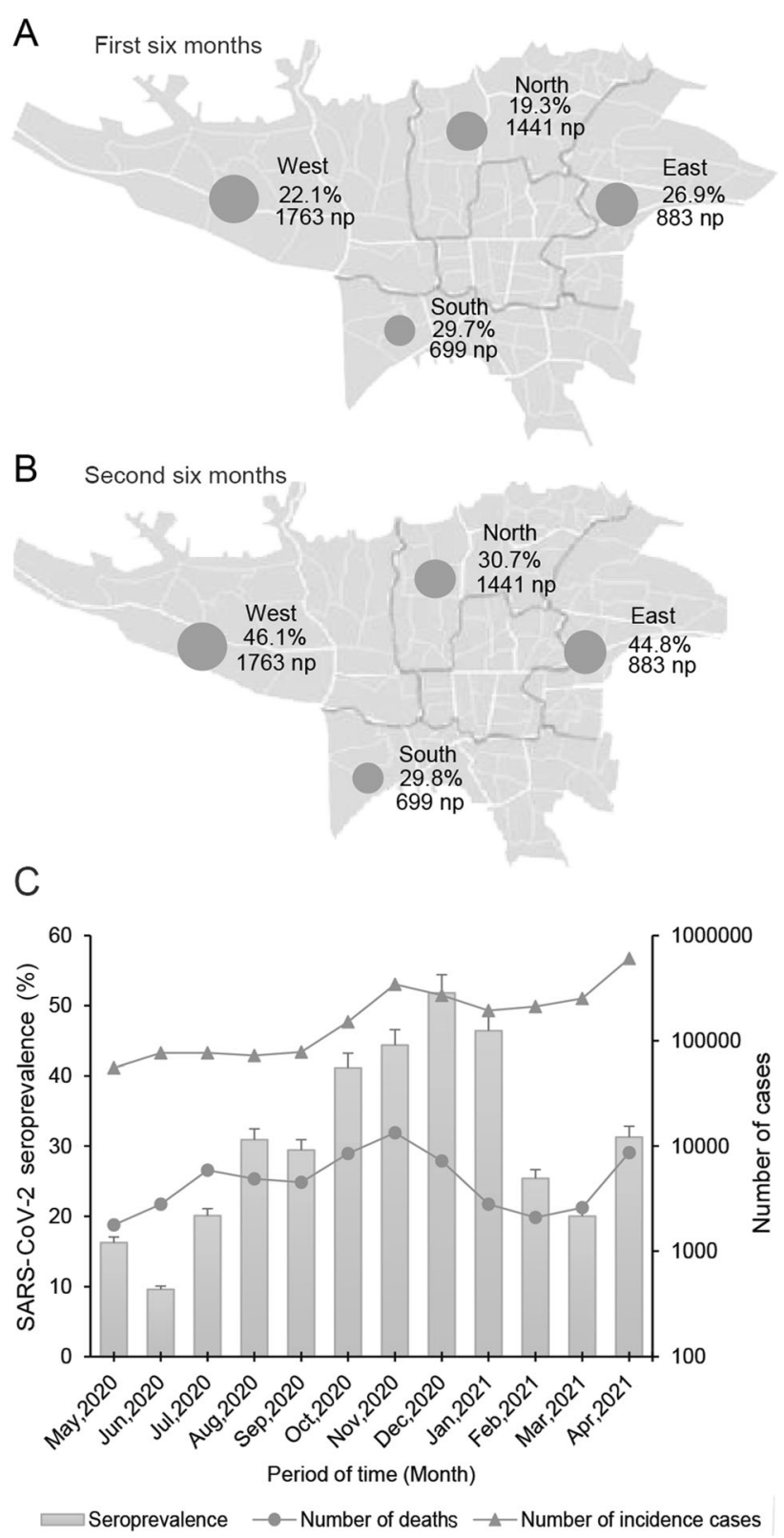

Fig. 1 Seroprevalence of SARS-CoV-2 in 4 regional districts of residence in Tehran in the first (A) and second six months $(\mathbf{B})$ of the study period. Variation of SARS-CoV-2 seroprevalence using IgG and/or IgM positivity in this study was compared to the incidence and death cases of COVID-19 reported by the Ministry of Health from all over the country during mentioned 12 months $(\mathbf{C})$. The error bars indicate $95 \%$ confidence intervals. np: number of populations.

the vaccination campaign in Iran) was longer than the other studies.

Moreover, this seroprevalence was higher than that showed in most studies performed in the other regions such as Seoul, Korea (0.07\%) (Noh et al. 2020), Niger State, Nigeria (25.4\%) (Majiya et al. 2020), Bonn, Germany (0.97\%) (Aziz et al. 2021) and Wuhan, China (6.92\%) (He et al. 2021). 
Table 1 SARS-CoV-2 IgM and IgG seroprevalence based on the age groups and sex from May 12020 to April 302021 in Tehran, Iran.

\begin{tabular}{|c|c|c|c|c|c|c|c|c|c|}
\hline \multicolumn{2}{|c|}{ Time period and age groups } & \multicolumn{3}{|c|}{$\begin{array}{l}\text { Number of IgM positive cases } \\
n / N\end{array}$} & \multirow[t]{2}{*}{$P$ value } & \multicolumn{3}{|c|}{$\begin{array}{l}\text { Number of IgG positive cases } \\
\mathrm{n} / \mathrm{N}\end{array}$} & \multirow[t]{2}{*}{$P$ value } \\
\hline & & Male & Female & Total & & Male & Female & Total & \\
\hline \multirow[t]{10}{*}{ May-June 2020} & Under 18 & $1 / 51$ & $0 / 32$ & $1 / 83$ & 0.42 & $3 / 51$ & $5 / 32$ & $8 / 83$ & 0.26 \\
\hline & & $(1.96 \%)$ & $(0.0 \%)$ & $(1.2 \%)$ & & $(5.8 \%)$ & $(15.6 \%)$ & $(9.6 \%)$ & \\
\hline & $19-34$ & $3 / 103$ & $2 / 71$ & $5 / 174$ & 0.65 & $10 / 103$ & $3 / 71$ & $13 / 174$ & 0.38 \\
\hline & & $(12.5 \%)$ & $(2.8 \%)$ & $(2.8 \%)$ & & $(9.7 \%)$ & $(4.2 \%)$ & $(7.4 \%)$ & \\
\hline & $35-49$ & $5 / 141$ & $5 / 67$ & $10 / 208$ & 0.34 & $12 / 141$ & $2 / 67$ & $14 / 208$ & 0.15 \\
\hline & & $(3.5 \%)$ & $(7.4 \%)$ & $(4.8)$ & & $(8.5 \%)$ & $(2.9 \%)$ & $(6.7 \%)$ & \\
\hline & $50-64$ & $3 / 40$ & $5 / 42$ & $8 / 82$ & 0.5 & $7 / 40$ & $11 / 42$ & $18 / 82$ & 0.34 \\
\hline & & $(7.5 \%)$ & $(12 \%)$ & $(9.8 \%)$ & & $(17.5 \%)$ & $(26.1 \%)$ & $(21.9 \%)$ & \\
\hline & $\geq 65$ & $1 / 14$ & $1 / 12$ & $2 / 26$ & 0.9 & $1 / 14$ & $2 / 12$ & $3 / 26$ & 0.5 \\
\hline & & $(7.14 \%)$ & $(8.3 \%)$ & $(7.7 \%)$ & & $(7.1 \%)$ & $(16.6 \%)$ & $(11.5 \%)$ & \\
\hline \multirow[t]{10}{*}{ July-August 2020} & Under18 & $1 / 67$ & $3 / 67$ & $4 / 135$ & 0.8 & $16 / 67$ & $10 / 67$ & $26 / 135$ & 0.5 \\
\hline & & $(1.4 \%)$ & $(4.4 \%)$ & $(3 \%)$ & & $(23.8 \%)$ & $(14.9 \%)$ & $(19.2 \%)$ & \\
\hline & $19-34$ & $15 / 171$ & $12 / 196$ & $27 / 363$ & 0.3 & $21 / 171$ & $18 / 196$ & $39 / 363$ & 0.6 \\
\hline & & $(8.8 \%)$ & $(6.1 \%)$ & $(7.4 \%)$ & & $(12.2 \%)$ & $(9.1 \%)$ & $(10.7 \%)$ & \\
\hline & $35-49$ & $43 / 217$ & $20 / 209$ & $63 / 426$ & 0.01 & $47 / 217$ & $40 / 209$ & $87 / 426$ & 0.7 \\
\hline & & $(19.8 \%)$ & $(9.5 \%)$ & $(15 \%)$ & & $(21.6 \%)$ & $(19.1 \%)$ & $(20.4 \%)$ & \\
\hline & $50-64$ & $22 / 104$ & $20 / 103$ & $42 / 207$ & 0.7 & $36 / 104$ & $30 / 103$ & $66 / 207$ & 0.2 \\
\hline & & $(21 \%)$ & $(19 \%)$ & $(20 \%)$ & & $(34.6 \%)$ & $(29.1 \%)$ & $(31.8 \%)$ & \\
\hline & $\geq 65$ & $6 / 38$ & $13 / 52$ & $19 / 90$ & 0.4 & $10 / 38$ & $21 / 52$ & $31 / 90$ & 0.16 \\
\hline & & $(15.7 \%)$ & $(25 \%)$ & $(21 \%)$ & & $(26.3 \%)$ & $(40.3 \%)$ & $(34.4 \%)$ & \\
\hline \multirow[t]{10}{*}{ September-October 2020} & Under18 & $9 / 67$ & $1 / 57$ & $10 / 124$ & 0.02 & $19 / 67$ & $11 / 57$ & $30 / 124$ & 0.29 \\
\hline & & $(13 \%)$ & $(1.8 \%)$ & $(8 \%)$ & & $(28.3 \%)$ & $(19.2 \%)$ & $(24.1 \%)$ & \\
\hline & $19-34$ & $33 / 187$ & $29 / 204$ & $62 / 391$ & 0.12 & $50 / 187$ & $60 / 203$ & $110 / 390$ & 0.07 \\
\hline & & $(17.7 \%)$ & $(14.2 \%)$ & $(15.8 \%)$ & & $(26.7 \%)$ & $(29.5 \%)$ & $(28.2 \%)$ & \\
\hline & $35-49$ & $50 / 234$ & $45 / 211$ & $95 / 445$ & 0.6 & $73 / 234$ & $74 / 211$ & $147 / 444$ & 0.52 \\
\hline & & $(21.3 \%)$ & $(21.3 \%)$ & $(21.3 \%)$ & & $(31.1 \%)$ & $(35 \%)$ & $(33 \%)$ & \\
\hline & $50-64$ & $37 / 114$ & $42 / 151$ & $79 / 265$ & 0.12 & $43 / 114$ & $65 / 151$ & $108 / 265$ & 0.61 \\
\hline & & $(32.4 \%)$ & $(27.8 \%)$ & $(29.8 \%)$ & & $(37.7 \%)$ & $(43 \%)$ & $(40.7 \%)$ & \\
\hline & $\geq 65$ & $39 / 79$ & $22 / 85$ & $55 / 164$ & 0.03 & $38 / 79$ & $34 / 85$ & $72 / 164$ & 0.38 \\
\hline & & $(49.3 \%)$ & $(25.8 \%)$ & $(33.5 \%)$ & & $(48 \%)$ & $(40 \%)$ & $(43.9 \%)$ & \\
\hline \multirow[t]{10}{*}{ November-December 2020} & Under18 & $4 / 33$ & $3 / 27$ & $7 / 60$ & 0.9 & $11 / 33$ & $7 / 27$ & $18 / 60$ & 0.51 \\
\hline & & $(12.1 \%)$ & $(11.1 \%)$ & $(11.6 \%)$ & & $(33.3 \%)$ & $(25.9 \%)$ & $(30 \%)$ & \\
\hline & $19-34$ & $27 / 134$ & $16 / 157$ & $43 / 291$ & 0.07 & $53 / 134$ & $54 / 157$ & $107 / 291$ & 0.51 \\
\hline & & $(20.1 \%)$ & $(10.1 \%)$ & $(14.7 \%)$ & & $(39.5 \%)$ & $(34.3 \%)$ & $(36.7 \%)$ & \\
\hline & $35-49$ & $34 / 170$ & $35 / 181$ & $69 / 351$ & 0.98 & $61 / 170$ & $86 / 181$ & $147 / 351$ & 0.04 \\
\hline & & $(20 \%)$ & $(19.3 \%)$ & $(19.6 \%)$ & & $(35.8 \%)$ & $(47.5 \%)$ & $(41.8 \%)$ & \\
\hline & $50-64$ & $37 / 106$ & $45 / 154$ & $82 / 260$ & 0.62 & $61 / 106$ & $82 / 154$ & $143 / 260$ & 0.76 \\
\hline & & $(34.9 \%)$ & $(29.2 \%)$ & $(31.5 \%)$ & & $(57.5 \%)$ & $(53.2 \%)$ & $(55 \%)$ & \\
\hline & $\geq 65$ & $31 / 53$ & $28 / 59$ & $59 / 112$ & 0.33 & $41 / 53$ & $36 / 59$ & $77 / 112$ & 0.08 \\
\hline & & $(58.4 \%)$ & $(47.4 \%)$ & $(52.6 \%)$ & & $(77.3 \%)$ & $(61 \%)$ & $(68.7 \%)$ & \\
\hline \multirow[t]{10}{*}{ January-February 2021} & Under18 & $0 / 12$ & $0 / 8$ & $0 / 20$ & 0.4 & $3 / 12$ & $2 / 8$ & $5 / 20$ & 1 \\
\hline & & $(0 \%)$ & $(0 \%)$ & $(0 \%)$ & & $(25 \%)$ & $(25 \%)$ & $(25 \%)$ & \\
\hline & $19-34$ & $4 / 36$ & $1 / 40$ & $5 / 76$ & 0.09 & $13 / 36$ & $15 / 40$ & $28 / 76$ & 0.83 \\
\hline & & $(11.1 \%)$ & $(2.5 \%)$ & $(6.5 \%)$ & & $(36.1 \%)$ & $(37.5 \%)$ & $(36.8 \%)$ & \\
\hline & $35-49$ & $6 / 43$ & $3 / 60$ & $9 / 103$ & 0.11 & $17 / 43$ & $16 / 60$ & $33 / 103$ & 0.38 \\
\hline & & $(13.9 \%)$ & $(5 \%)$ & $(8.7 \%)$ & & $(39.5 \%)$ & $(26.6 \%)$ & $(32 \%)$ & \\
\hline & $50-64$ & $2 / 26$ & $5 / 37$ & $7 / 63$ & 0.75 & $9 / 26$ & $15 / 37$ & $24 / 63$ & 0.22 \\
\hline & & $(7.6 \%)$ & $(13.5 \%)$ & $(11.1 \%)$ & & $(34.6 \%)$ & $(40.5 \%)$ & $(38 \%)$ & \\
\hline & $\geq 65$ & $3 / 11$ & $3 / 21$ & $6 / 32$ & 0.53 & $6 / 11$ & $10 / 21$ & $16 / 32$ & 0.71 \\
\hline & & $(27.2 \%)$ & $(14.2 \%)$ & $(18.7 \%)$ & & $(54.5 \%)$ & $(47.6 \%)$ & $(50 \%)$ & \\
\hline
\end{tabular}


Table 1 (continued)

\begin{tabular}{|c|c|c|c|c|c|c|c|c|c|}
\hline \multirow[t]{2}{*}{ Time period and age groups } & & \multicolumn{3}{|c|}{$\begin{array}{l}\text { Number of IgM positive cases } \\
\mathrm{n} / \mathrm{N}\end{array}$} & \multirow[t]{2}{*}{$P$ value } & \multicolumn{3}{|c|}{$\begin{array}{l}\text { Number of IgG positive cases } \\
\mathrm{n} / \mathrm{N}\end{array}$} & \multirow[t]{2}{*}{$P$ value } \\
\hline & & Male & Female & Total & & Male & Female & Total & \\
\hline \multirow[t]{5}{*}{ March-April 2021} & Under18 & $\begin{array}{l}0 / 8 \\
(0 \%)\end{array}$ & $\begin{array}{l}2 / 10 \\
(20 \%)\end{array}$ & $\begin{array}{l}2 / 18 \\
(11.1 \%)\end{array}$ & 0.18 & $\begin{array}{l}2 / 8 \\
(25 \%)\end{array}$ & $\begin{array}{l}3 / 10 \\
(30 \%)\end{array}$ & $\begin{array}{l}5 / 18 \\
(27.7 \%)\end{array}$ & 0.61 \\
\hline & $19-34$ & $\begin{array}{l}5 / 62 \\
(8 \%)\end{array}$ & $\begin{array}{l}5 / 67 \\
(7.4 \%)\end{array}$ & $\begin{array}{l}10 / 129 \\
(7.7 \%)\end{array}$ & 0.9 & $\begin{array}{l}9 / 62 \\
(14.5 \%)\end{array}$ & $\begin{array}{l}8 / 67 \\
(11.9 \%)\end{array}$ & $\begin{array}{l}17 / 129 \\
(13.1 \%)\end{array}$ & 0.78 \\
\hline & $35-49$ & $\begin{array}{l}12 / 74 \\
(16.2 \%)\end{array}$ & $\begin{array}{l}2 / 65 \\
(3 \%)\end{array}$ & $\begin{array}{l}14 / 139 \\
(10 \%)\end{array}$ & 0.01 & $\begin{array}{l}21 / 74 \\
(28.3 \%)\end{array}$ & $\begin{array}{l}13 / 65 \\
(20 \%)\end{array}$ & $\begin{array}{l}34 / 139 \\
(24.4 \%)\end{array}$ & 0.47 \\
\hline & $50-64$ & $\begin{array}{l}5 / 22 \\
(22.7 \%)\end{array}$ & $\begin{array}{l}2 / 29 \\
(6.8 \%)\end{array}$ & $\begin{array}{l}7 / 51 \\
(13.7 \%)\end{array}$ & 0.12 & $\begin{array}{l}10 / 22 \\
(45.4 \%)\end{array}$ & $\begin{array}{l}8 / 29 \\
(27.5 \%)\end{array}$ & $\begin{array}{l}18 / 51 \\
(35.2 \%)\end{array}$ & 0.17 \\
\hline & $\geq 65$ & $\begin{array}{l}8 / 11 \\
(72.7 \%)\end{array}$ & $\begin{array}{l}4 / 19 \\
(21 \%)\end{array}$ & $\begin{array}{l}12 / 30 \\
(40 \%)\end{array}$ & 0.00 & $\begin{array}{l}10 / 11 \\
(90.9 \%)\end{array}$ & $\begin{array}{l}8 / 19 \\
(42.1 \%)\end{array}$ & $\begin{array}{l}18 / 30 \\
(60 \%)\end{array}$ & 0.03 \\
\hline
\end{tabular}

$\mathrm{n}$ : number of positive cases, $\mathrm{N}$ : total number of cases.

It is worth noting that, populations in most of the mentioned researches were randomly selected. However, in this research, all participants were referred to private laboratories to evaluate the humoral immunity against SARSCoV-2, which might mean that they had a known exposure to SARS-CoV-2 or presented suspicious clinical features of COVID-19. Consequently, the results might not mirror the normal population and it should have overestimated the seroprevalence of SARS-CoV-2 in Tehran.

A remarkable point is that, SARS-CoV-2 seroprevalence in different researches is affected by the time periods of the study. As time covers the pandemic, the rate of seroprevalence increases. This rise was shown in the present study as well. During May 1 to October 31, 2020, prevalence of antibodies against SARS-CoV-2 in the south of the city was higher $(151 / 502,30 \%)$ than that in the north $(186 /$ $960,19 \%$ ), which might be due to divergent lifestyles, density of population and socioeconomic status in the south and north of Tehran. However, during November 1, 2020 to April 30, 2021, extensive seroconversion in the north, west and east of Tehran was noted. These increases in mentioned regions could be attributed to the third wave of COVID-19 circulation which was greater than the first two waves and UK B1.1.7 variant circulation in Tehran. Given the high transmissibility of this variant, it could cause the raise of SARS-CoV-2 seroprevalence during the last three months (February to April) in Tehran (The data was shown in Fig. 1) It is worth mentioning that comparison of seroprevalence in the south of Tehran between mentioned periods of time revealed no changes (Fig. 1A and 1B). This constancy might be caused by the level of herd immunity which raised up in the south of the city sooner than the other regions.

In conclusion, this study was the first report of SARSCoV-2 IgG and IgM seroprevalence in four regional districts of Tehran, Iran. The results showed from May 1,
2020 to April 30, 2021, the last 12 months before the start of the vaccination campaign, the seroprevalence of SARSCoV-2 has increased in the city. However, the level of SARS-CoV-2 seropositivity was not sufficient to stop virus circulation and avoid the next COVID-19 incidence peak. During the coming months, the level of seropositivity would be increasing by natural infection and vaccination.

Acknowledgements The authors would like to thank Dr. Namazi, Dr. Talachi, Dr. Nadji and Dr. Lashgari, who helped us in data collection.

\section{Compliance With Ethical Standards}

Conflict of interest The authors declare that there are no conflicts of interests.

Animal and Human Rights Statement The study was conducted in accordance with the Declaration of Helsinki and national and institutional standards and it was approved by laboratories ethics review board. Participants signed written informed consents and accepted the publication of data for research.

\section{References}

Abduljalil JM (2020) Laboratory diagnosis of SARS-CoV-2: available approaches and limitations. New Microbes New Infect 36:100713

Aziz NA, Corman VM, Echterhoff AK, Müller MA, Richter A, Schmandke A, Schmidt ML, Schmidt TH, de Vries FM, Drosten C (2021) Seroprevalence and correlates of SARS-CoV-2 neutralizing antibodies from a population-based study in Bonn, Germany. Nat Commun 12:1-10

Havers FP, Reed C, Lim T, Montgomery JM, Klena JD, Hall AJ, Fry AM, Cannon DL, Chiang C-F, Gibbons A (2020) Seroprevalence of antibodies to SARS-CoV-2 in 10 sites in the United States, March 23-May 12, 2020. JAMA 180:1576-1586

He Z, Ren L, Yang J, Guo L, Feng L, Ma C, Wang X, Leng Z, Tong $X$, Zhou W (2021) Seroprevalence and humoral immune durability of anti-SARS-CoV-2 antibodies in Wuhan, China: a longitudinal, population-level, cross-sectional study. Lancet 397:1075-1084 
Long QX, Tang XJ, Shi QL, Li Q, Deng HJ, Yuan J, Hu JL, Xu W, Zhang Y, Lv FJ, Su K, Zhang F, Gong J, Wu B, Liu XM, Li JJ, Qiu JF, Chen J, Huang AL (2020) Clinical and immunological assessment of asymptomatic SARS-CoV-2 infections. Nat Med 26:1200-1204

Majiya H, Aliyu-Paiko M, Balogu VJE (2020) Seroprevalence of COVID-19 in Niger State. medRxiv. https://doi.org/10.1101/ 2020.08.04.20168112

Noh JY, Seo YB, Yoon JG, Seong H, Hyun H, Lee J, Lee N, Jung S, Park M-J, Song W et al. (2020) Seroprevalence of anti-SARSCoV-2 antibodies among outpatients in southwestern Seoul, Korea. J Korean Med Sci 35:e311

Patel R, Babady E, Theel ES, Storch GA, Pinsky BA, George KS, Smith TC, Bertuzzi S (2020) Report from the American Society for Microbiology COVID-19 international summit, 23 march 2020: value of diagnostic testing for SARS-CoV-2/COVID-19. mBio 11:e00722-20

Pollán M, Pérez-Gómez B, Pastor-Barriuso R, Oteo J, Hernán MA, Pérez-Olmeda M, Sanmartín JL, Fernández-García A, Cruz I, de Larrea NF (2020) Prevalence of SARS-CoV-2 in Spain (ENECOVID): a nationwide, population-based seroepidemiological study. Lancet 396:535-544

Poustchi H, Darvishian M, Mohammadi Z, Shayanrad A, Delavari A, Bahadorimonfared A, Eslami S, Javanmard SH, Shakiba E, Somi
MH (2021) SARS-CoV-2 antibody seroprevalence in the general population and high-risk occupational groups across 18 cities in Iran: a population-based cross-sectional study. Lancet Infect Dis $21: 473-481$

Rostami A, Sepidarkish M, Leeflang M, Riahi SM, Shiadeh MN, Esfandyari S, Mokdad AH, Hotez PJ, Gasser RB (2021) SARS$\mathrm{CoV}-2$ seroprevalence worldwide: a systematic review and metaanalysis. Clin Microbiol Infect 27:331-340

Shakiba M, Nazemipour M, Salari A, Mehrabian F, Nazari SSH, Rezvani SM, Ghasempour Z, Heidarzadeh A, Mansournia MA (2021) Seroprevalence of SARS-CoV-2 in Guilan Province, Iran, April 2020. Emerg Infect Dis 27:636-638

Vena A, Berruti M, Adessi A, Blumetti P, Brignole M, Colognato R, Gaggioli G, Giacobbe DR, Bracci-Laudiero L, Magnasco L (2020) Prevalence of antibodies to SARS-CoV-2 in Italian adults and associated risk factors. J Clin Med 9:2780

Watson J, Richter A, Deeks JJb (2020) Testing for SARS-CoV-2 antibodies. BMJ 370:m3325

Yavarian J, Shafiei-Jandaghi N-Z, Sadeghi K, Malekshahi SS, Salimi V, Nejati A, Aja-Minejad F, Ghavvami N, Saadatmand F, Mahfouzi S (2020) First Cases of SARS-CoV-2 in Iran, 2020: Case Series Report. Iran J Public Health 49:1564 